\title{
REVISION SOBRE LA BIOLOGIA DE Rhipicephalus sanguineus (ARTHROPODA, CHELICERATA)(LATREILLE, 1806).
}

\section{REVIEW ON THE BIOLOGY OF Rhipicephalus sanguineus (ARTHROPODA, CHELICERATA)(LATREILLE, 1806).}

\author{
Romina Álvarez. \\ Hospital Clínico Veterinario Comunal Ltda, Salvador 771-B, Providencia, Santiago. \\ Email: romina.alvarezrivas@gmail.com
}

Recibido: 03 de febrero de 2017; Aceptado: 04 de abril de 2017.

RESUMEN

Las garrapatas, corresponden a un grupo de arácnidos ectoparásitos, los cuales afectan principalmente a vertebrados terrestres, su identificación se hace por medio de análisis morfométricos y moleculares. Dentro de este grupo se encuentra Rhipicephalus sanguineus el cual afecta poblaciones de perros domésticos, esta especie de amplia distribución geográfica en el territorio chileno, y es de alta importancia, porque es un agente transmisor de enfermedades que podrían afectar a los hospedadores, así como a las poblaciones humanas asociadas. En la presente revisión, se describe brevemente el ciclo de vida y la biología de $R$. sanguineus y se comentan las implicancias para efectos de sanidad ambiental.

Palabras clave: infestación, Infestación, Rhipicephalus sanguineus, ectoparásitos

\section{ABSTRACT}

Ticks correspond to a group of ectoparasite arachnids, which mainly affect terrestrial vertebrates, their identification is done through morphological and molecular analyzes. Within this group is Rhipicephalus sanguineus the type of population of domestic dogs, this species of wide geographic distribution in the Chilean territory, and is of high importance, because it is a transmitter of diseases that affect the hosts, as well as a Las Populations. In the present review, the life cycle and biology of $\mathrm{R}$. 
sanguineus are briefly described and the implications for environmental health effects are discussed.

Key words: infestation, Infestation, Rhipicephalus sanguineus, ectoparasites.

\section{INTRODUCCION}

En el mundo, existen más de 800 especies de garrapatas. Taxonómicamente estos ectoparásitos pertenecen al Phylum Artrópoda, clase Arácnida, subclase Acarina, orden Parasitiforme, suborden Ixodida (Parola y Raoult, 2001).

Dentro de este suborden se han descrito tres familias: Argasidae o garrapatas blandas; la cual está comprendida por la subfamilia Argasinae y Ornithodorinae, representando a 177 especies. Ixodidae o garrapatas duras; esta familia comprende dos grupos principales: Prostriata y Metastriata que están compuestas por 692 especies y por último existe la familia Nuttalliellidae; que está representada por una sola especie que carece de interés sanitario (Figura 1) (Parola y Raoult, 2001).

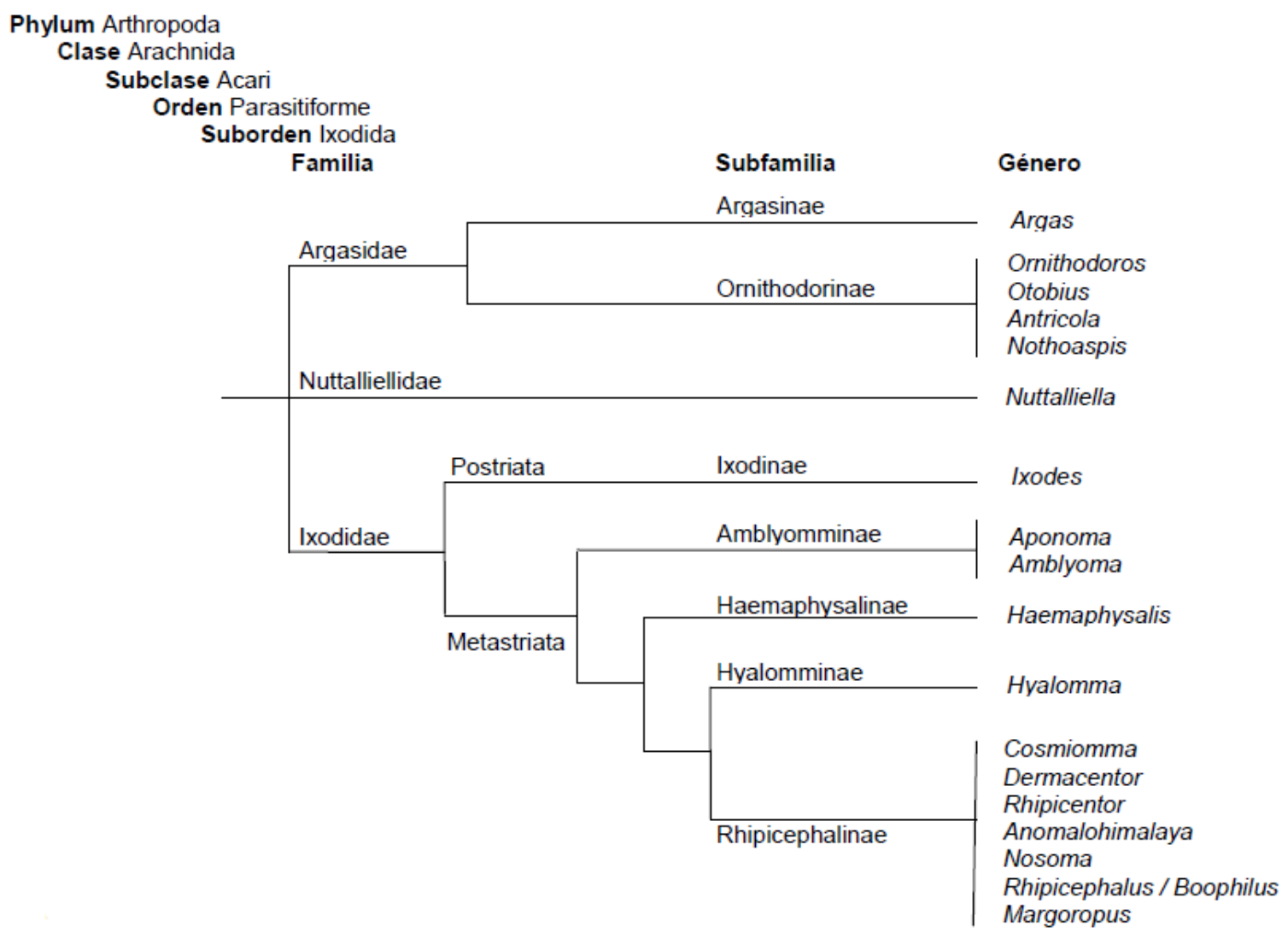

Figura 1: Clasificación taxonómica de las garrapatas (Parola y Raoult 2001). 
En referencia a la estructura general, el cuerpo de las garrapatas duras se divide en dos secciones, la gnatosoma anterior e idiosoma posterior. En el gnatosoma (capitullum) se encuentran un par de palpos segmentados, que son órganos sensoriales simples que ayudan a las garrapatas a localizar el huésped. El escudo es una placa dorsal esclerosada posterior al capitulum, esta estructura y el gnatosoma varía según la especie (Figura 2), lo cual puede aportar en la identificación de las garrapatas. En el macho el escudo cubre completamente el dorso, mientras que en la hembra lo cubre parcialmente (Figura 3), esto debido a que la ingesta de sangre es mucho mayor (Quiroz, 2005).

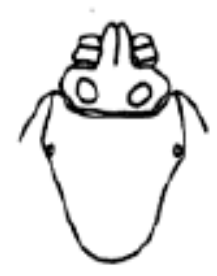

A

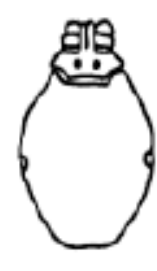

B

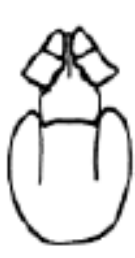

C

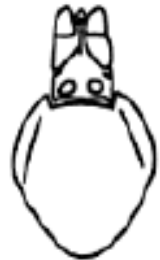

D

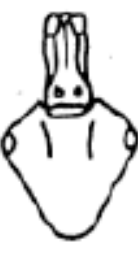

E

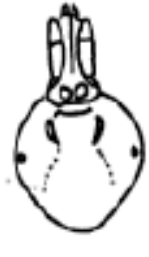

$\mathbf{F}$

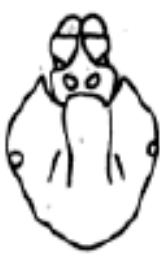

G

Figura 2: Escudo y Gnatosoma de hembras. A. Boophilus; B. Rhipicephalus; C. Haemaphusalis; D. Ixodes; E. Amblyomma; F. Hyalomma; G. Dermacentor; H. Boophilus annulatus (Quiroz, 2005).

La identificación de Rhipicephalus sanguineus, se basa en las diferencias morfológicas que presentan en relación a las otras especies. La base del capítulo es hexagonal (figura 2B) y el escudo es marrón claro, sin ornamentación y con festones (figura 3). La coxa I presenta una hendidura formando dos espinas muy cercanas y las coxas II, III y IV poseen un diente externo corto y un tubérculo romo en el ángulo posterior interno (Izquierdo, 2012).

Por otra parte, las herramientas moleculares actuales han permitido muchos avances en el campo de las relaciones filogenéticas de las garrapatas, pudiendo establecer relaciones cercanas entre diferentes tipos (Barker y Murrell, 2004). La identificación se lleva a cabo mediante biología molecular empleando PCR que amplifica un fragmento de 456 pb del gen ARNr $16 \mathrm{~S}$ de las garrapatas. En el caso de las garrapatas del género Rhipicephalus 5 se lleva a cabo además otra reacción de PCR del gen ARNr 12S mitocondrial (Santibáñez, 2012). 


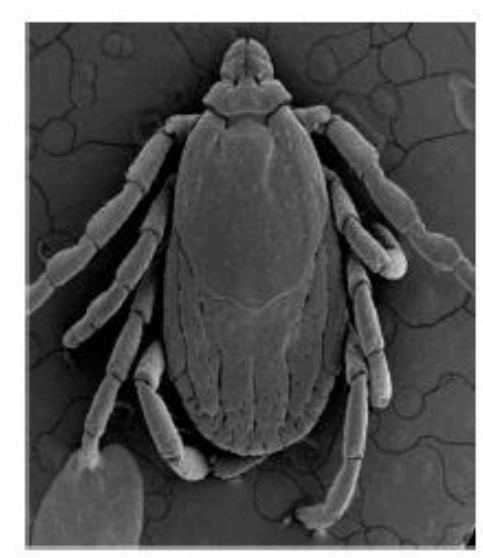

Figura 3: Vista dorsal de Rhipicephalus sanguineus hembra; la base del capítulo hexagonal, palpos cortos, escudo liso sin ornamentaciones y con la presencia de festones (Márquez et al., 2005).

La distribución geográfica de Rhipicephalus sanguineus es de carácter mundial, esta abarca de los $50^{\circ}$ latitud norte y $35^{\circ}$ latitud sur (Ramírez et al., 2008). En Chile se han identificado tres especies de garrapatas caninas: Rhipicephalus sanguineus, Amblyomma tigrinum en zonas rurales de la zona centro sur del país y Amblyomma triste en un sector rural cercano a Arica (Abarca et al., 2013).

Rhipicephalus sanguineus presenta tres formas parasitarias dentro de su ciclo de vida: larva, ninfa y adulto (Figura 4). El ciclo comienza cuando los huevos eclosionan y en un periodo de 6 días a varias semanas después se convierten en larvas de seis patas. A bordo de su hospedador estas larvas se alimentan de sangre durante 3 a 10 días y posteriormente caen al suelo donde experimentan la muda larval, este proceso tiene una duración de 5 a 15 días donde posteriormente pasan a su siguiente estado móvil de ninfa (Labruna, 2004). Las ninfas se arriman a su hospedador y se alimentan de 3 a 11 días, después de este periodo de tiempo dejan a su hospedador para poder mudar nuevamente (Quiroz, 2005). En condiciones favorables a los 63 días se convierten en machos y hembras adultas listas para parasitar a su tercer hospedador, donde se alimentan y reproducen. La hembra luego de estar abastecida con suficiente sangre y fecundada, se deja caer al suelo donde pone de 1.000 a 3.000 huevos en un periodo de tres meses, reiniciando el ciclo (Labruna, 2004). 


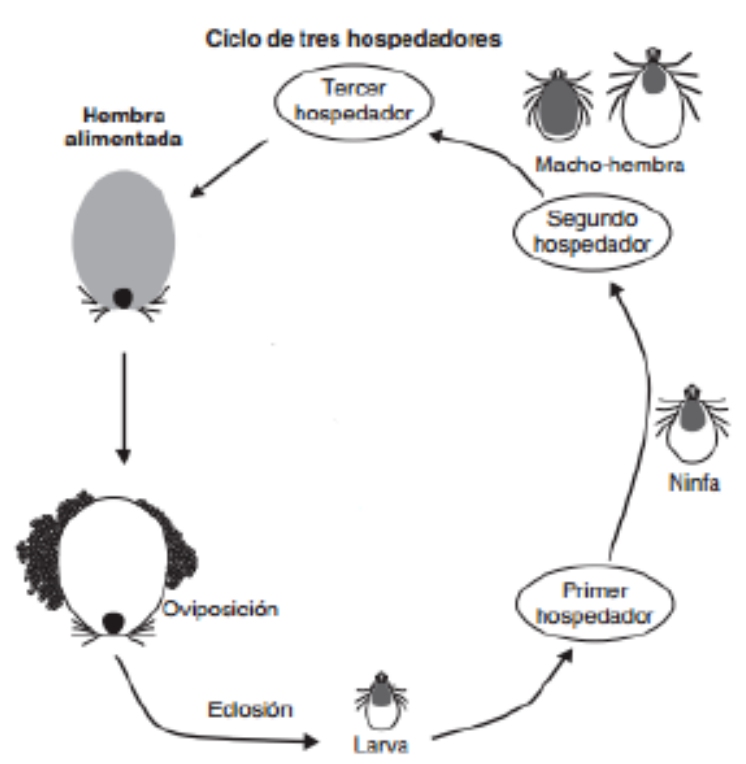

Figura 4: Ciclo biológico de Rhipicephalus sanguineus (Márquez et al., 2005).

Las enfermedades que transmiten las garrapatas son uno de los grandes problemas de salud pública y veterinaria que existen a nivel mundial. Entre los principales agentes infecciosos que puede transmitir Rhipicephalus sanguineus a los caninos se encuentran: Ehrlichia canis, Babesia canis, Rickettsia ricketsii, Rickettsia conorii, Hepatozoon canis, Haemobartonella canis (Izquierdo, 2012), los cuales pueden ser adquiridos por las garrapatas mediante dos vías: La primera es por el proceso de alimentación hematófaga y es llamada transmisión transestadial; la garrapata se alimenta de un hospedador infectado y posterior a esto muda. En la siguiente fase estadial pasa a alimentarse de otro hospedador transmitiendo el agente infeccioso adquirido. El segundo tipo de transmisión es transovárica que se da cuando el agente infecta a los huevos y como consecuencia, las larvas van a ser portadoras y vectores potenciales para el agente infeccioso (Ramírez, 2014).

El creciente contacto entre mascotas y humanos ha favorecido el rol zoonótico relacionado con garrapatas, constituyendo un riesgo para la salud humana y animal.

\section{REFERENCIAS}

Abarca, K., López, J., González, P., Dabanch, J., Torres, M., Solari, V., Perret, C. 2008. Evidencia seroepidemiológica de exposición humana a Anaplasma $s p$ en Santiago, Chile. Revista Chilena de Infectología, 25: 360. 
Izquierdo, C. 2012. Importancia de la garrapata (Rhipicephalus sanguineus) como vector de enfermedades infecciosas en la clínica de perros y en la salud pública: Estudio recapitulativo. Tesis de Grado. Universidad Veracruzana, Facultad de medicina veterinaria y zootecnia. Veracruz, México.

Labruna, M. 2004. Biológica - Ecología de Rhipicephalus sanguineus (Acari: Ixodidae). Revista Brasileira de Parasitolologia Veterinaria, 13 (suppl 1): 123-124.

Márquez, F., Hidalgo, A., Contreras, F., Rodríguez, J., Muniain, M. 2005. Las garrapatas (Acarina: Ixodida) como transmisores y reservorios de microorganismos patógenos en España. Enfermedades Infecciosas y Microbiología Clínica, 23: 94-102.

Parola, P., Raoult, D. 2001. Ticks and Tickborne Bacterial Diseases in Humans: An Emerging Infectious Threat. Ticks and Tickborne Diseases, 32: 899.

Quiroz, H. 2005. Parasitología y enfermedades parasitarias de animales domésticos. Ed. México D.F: Editorial Limusa. 765,779 pp..

Ramírez., A. 2014. Identificación Molecular y Análisis de la Relación Filogenética de Especies de Rickettsias Presentes en Garrapatas Provenientes de Tres Regiones de Colombia. Tesis Magister. Universidad Nacional de Colombia, Facultad de Medicina. Bogotá D.C., Colombia.

Santibáñez, S. 2012. Rendimiento de diferentes métodos de PCR en el diagnóstico molecular de las Rickettsiosis humanas transmitidas por garrapatas. Tesis Doctoral. Universidad de la Rioja, España. 